\title{
Matching ICT Skills Competency and Industry Need: Basis for Curriculum Enhancement
}

\author{
Arvin V. Duhaylungsod, MEnggEd \\ aduhaylungsod@gmail.com \\ Zamboanga Peninsula Polytechnic State University, R.T. Lim Boulevard, Baliwasan, Zamboanga City 7000, Philippines
}

\begin{abstract}
The main objective of the study was to determine the matching ICT skills competency and Industry need as a Basis for Curriculum enhancement in the BS Information Technology Program. The study also evaluates the level of competency or proficiency of the BSIT Graduates as required for an entry-level position in the IT Department as rated by the Academic and the Industry Sector. The study employed a descriptive-quantitative method. The results identified that both sectors described that Technical Support Specialist, System Administrator, Web and Applications Developer, Network Engineer and Computer Programmer are extremely required jobs in a company. They also agreed that their professional and common course in terms of competency or proficiency in Database Management System, Networking I and Networking II, System Analysis and Design, System Administration \& Maintenance, Computer Programming \& Web Programming and Development are described as experts as these competencies are very much required and in-demand jobs for today's industry. This means that State Universities and Colleges (SUCs) private Higher Education Institutions (HEIs) and the different industry sectors in the Zamboanga Peninsula have the same requirements in hiring BSIT graduates for an entrylevel position that have acquired ICT skills experts in their professional and common courses.
\end{abstract}

Keywords: Information Technology, Curriculum, ICT Descriptive-Quantitative Analysis, Philippines

\section{Introduction}

Technology is constantly developing, several sectors, both private and government-run, are adopting and formulating new techniques or strategies to reach their specific aims and objectives to become more productive. That is why the industry requires a trained and knowledgeable workforce, particularly in the field of Information and Communication Technology (ICT), to use and manage various ICT technologies that are now linked or integrated with today's industry's system. In the last ten years, industries such as AgriculturalAquatic, Manufacturing, and Commercial have incorporated ICT into their basic systems of operations in the Philippines and overseas.

The integration of technologies to industry requires a needed workforce particularly in the field of Information and Communication Technology (ICT). In connection to this, the education system must also produce qualified and competent graduates that can do the job that is expected of them and be highly qualified to meet the demands and expectations of their employer. It is now the role of the State Universities and Colleges (SUCs) and private Higher Educational Institution (HEIs) in the Zamboanga Peninsula, Philippines to review the course they offer in Information and Communication Technology (ICT). Similarly, there is a gap in the curriculum alignment of ICT courses, particularly the Bachelor of Science in Information Technology (BSIT), with various industries since the process of reviewing the curriculum takes years, and the choice to 
reform the curriculum takes even longer. Given the passage of time, these industries' ICT departments change or upgrade digital systems every year, or as often as new technologies or systems are invented. This premise assumes that higher education's ICT abilities are no longer relevant to industry requirements.

As a result, the goal of the study is to map the ICT skills that companies require, as well as to determine their level of competency and proficiency. In addition, this study will determine which ICT skills should be included in the BSIT curriculum, or whether these ICT abilities may be used to create new sets of components for a new course offering.

\subsection{Objectives of the Study}

This study was conducted to determine the Matching ICT Skills Competency and Industry Need: Basis for Curriculum Enhancement in the BS Information Technology Program in the State Universities and Colleges (SUCs) and private Higher Educational Institutions (HEIs) in the Zamboanga Peninsula.

Specifically, it aimed to:

1. Identify the ICT skills required of a BSIT Graduate as a basis for an entry-level position for employment in the Industries.

2. Determine the level of competency or proficiency of the BSIT Graduates as required for an entry-level position in the IT Department.

3. Assess the significant difference in the level of competency or proficiency of the BSIT Graduates as required for an entry-level position in the IT Department as rated by the Academic and the Industry Sector.

\section{Methodology}

\subsection{Scope of the Study}

The IT managers and personnel of the Agricultural-Aquatic, Manufacturing, and Commercial industries are the participants of this study. The researcher also includes the Faculty of the different Universities and Colleges of the BSIT program in Zamboanga Peninsula as participants of which they can provide adequate answers to the survey questionnaires.

\subsection{Research Design}

The study utilized the Descriptive-Quantitative research design. The descriptive research technique was appropriate for this study which described the ICT skills required for an entry level position for employment in the industry of the BSIT graduate and their level of competency or proficiency. Quantitative research because it uses numerical data obtained from survey questionnaire to evaluate if the ICT skills and competencies of the BS Information Technology Curriculum match the ICT skills required for employment by different sectors of the industry in Agricultural-Aquatic, Manufacturing, and Commercial Industries.

\subsection{Population Sampling Design}

The study adopted the purposive non-random sampling design in the selection of participants specifically the employees under the managerial level and ICT personnel or ICT Staff of the Agricultural-Aquatic, Manufacturing, and Commercial Industry. Likewise, the faculty of BSIT program from different SUCs and HEI's. The researcher chose this form of sample technique because only selected personnel with ICT knowledge and abilities, in the researcher's opinion, can provide relevant responses to the survey questions. 


\subsection{Instruments}

The study evaluates the level of competency or proficiency of the BSIT Graduates as required for an entrylevel position in the IT Department as rated by the Academic and the Industry where the indicators were adopted from the curriculum of the BSIT program, Commission on Higher Education (CHED) Memorandum Order or CMO 25. S. 2015 of the BSIT Curriculum. However, the instruments were given to experts for the validity of its contents and construct.

\subsection{Ethical Consideration}

Appropriate research ethics and guidelines governed the investigation. The selected respondents received a consent letter for involvement in the study's conduct, as well as appropriate permission to answer the survey questionnaire. To protect the respondents' privacy, the respondents' confidentially was scrupulously protected and their identities were kept hidden. Any information obtained from any source was properly recognized through citation and referencing. As a result, the ethical element of the research was closely adhered to in this study. The researchers sought approval of the respondents to allow the researchers to present in the other forum or fora.

\subsection{Data Gathering Procedure}

The researcher sought permission from the management and administration of the various Industry and Academe to collect the necessary data. To collect data from selected Managerial Level personnel as well as ICT Personnel or IT Staff from each type of industry, the approved letter from the top management industry were presented to the selected employees for the collection of the data through survey questionnaires. The schedule distribution and retrieval were arranged with the top management of the different industries or to the Human Resource Management Personnel.

\subsection{Statistical Treatment of Data}

Weighted Mean. This measure was used to determine the ICT skills required for employment in the different industry sectors of Agricultural-Aquatic, Manufacturing, and Commercial Industry as well as to evaluate the proficiency or competency level of BSIT program offered as perceived to be required for an entry-level position in the different industry sectors in Agricultural-Aquatic, Manufacturing, and Commercial Industry.

T-test for Independent Samples was used since to evaluate the significant difference in the level of proficiency of the BSIT program required for an Entry-Level Position in the IT Department as rated by the Academic Faculty and Industry Sector.

\section{Findings and Discussion}

\subsection{Data Analysis}

Problem No. 1. What are the ICT skills required of a BSIT Graduate as a basis for an entry-level position for employment by the Agricultural-Aquatic, Manufacturing, and Commercial Industries? 
Table 1. ICT skills required of a BSIT Graduate as a basis for an entry-level position (Primary Job Role) for employment by the Agricultural-Aquatic, Manufacturing, and Commercial Industries as rated by the Industry Sector

\begin{tabular}{llcc} 
No & Primary Job Roles & Computed Mean & Description \\
\hline 1 & Web and Applications Developer & 4.27 & Extremely Required \\
\hline 2 & Junior Database Administrator & 3.98 & Highly Required \\
\hline 3 & Systems Administrator & 4.17 & Highly Required \\
\hline 4 & Network Engineer & 4.15 & Highly Required \\
\hline 5 & Junior Information Security Administrator & 3.63 & Highly Required \\
\hline 6 & Systems Integration Personnel & 3.57 & Highly Required \\
\hline 7 & IT Audit Assistant & 3.50 & Highly Required \\
\hline 8 & Technical Support Specialist & 4.43 & Extremely Required \\
\hline & GRAND MEAN & $\mathbf{3 . 9 6}$ & Highly Required
\end{tabular}

Legend: Extremely Required (ER) - 4.21 - 5.00; Highly Required (HR) - 3.41 - 4.20; Moderately Required (MR) - 2.61 - 3.40; Less Required (LR) - $1.81-2.60$; Not Required (NR) - $1.00-1.80$

Table 1, for a primary job position as rated by the Industry, the "Extremely Required" were the Technical Support Specialist mean and Web and Applications Developer with a mean score of 4.43 and 4.27. "Highly Required" were the Systems Administrator and Network Engineer mean score of 4.17 and 4.15. The Grand Mean was 3.96 with a descriptive value of "Highly Required".

Technical Support Specialist \& Web Application Developer are one of the 7 In-Demand ICT Careers in the Philippines listed in the website of (Bukas.ph, 2021).

Table 2. ICT skills required of a BSIT Graduate as a basis for an entry-level position (Secondary Job Role) for employment as rated by the Industry Sector

\begin{tabular}{llcc} 
No & Secondary Job Roles & Computed Mean & Description \\
\hline 1 & QA Specialist & 3.92 & Highly Required \\
\hline 2 & System Analyst & 4.00 & Highly Required \\
\hline 3 & Computer Programmer & 4.05 & Highly Required \\
\hline & GRAND MEAN & $\mathbf{3 . 9 9}$ & Highly Required
\end{tabular}

Table 2, For a secondary job position for employment as rated by the Industry Sector. The participants of the Industry Sector gave a Grand Mean Score of 3.99 with a descriptive value of "Highly Required" of which the highest rating is the Computer Programmer with a mean score of 4.05. According to Martinez (2018), as a student one needs to build skills in computer programming and operation that meet the current and future needs of the industries. (Miltner, 2017) underscored the idea that computer programming or "coding" is a necessary skill for the jobs of the future. 
Table 3. ICT skills required of a BSIT Graduate as a basis for an entry-level position (Primary Job Role) as rated by the Academic Sector

\begin{tabular}{llcc} 
No & Primary Job Roles & Computed Mean & Description \\
\hline 1 & Web and Applications Developer & 4.52 & Extremely Required \\
\hline 2 & Junior Database Administrator & 3.78 & Highly Required \\
\hline 3 & Systems Administrator & 4.77 & Extremely Required \\
\hline 4 & Network Engineer & 4.42 & Extremely Required \\
\hline 5 & Junior Information Security Administrator & 4.03 & Highly Required \\
\hline 6 & Systems Integration Personnel & 4.20 & Highly Required \\
\hline 7 & IT Audit Assistant & 3.93 & Highly Required \\
\hline 8 & Technical Support Specialist & 4.85 & Extremely Required \\
\hline & GRAND MEAN & $\mathbf{4 . 3 1}$ & Extremely Required
\end{tabular}

Table 3, The Technical Support Specialist, System Administrator, Web \& Applications Developer and Network Engineer regarded as "Extremely Required" with a mean score of 4.85, 4.52 \& 4.42. While "Highly Required" are the Systems Integration Personnel \& Junior Information Security Administrator with a mean score of $4.20 \& 4.03$. The Grand Mean response was 4.31 with a descriptive value of "Extremely Required".

Table 4. For an entry-level position (Secondary Job Role) as rated by the Academic Sector
No
Secondary Job Roles
Computed Mean
Description

\begin{tabular}{llcc}
\hline 1 & QA Specialist & 4.33 & Extremely Required \\
\hline 2 & System Analyst & 4.83 & Extremely Required \\
\hline 3 & Computer Programmer & 4.85 & Extremely Required \\
\hline & GRAND MEAN & $\mathbf{4 . 6 7}$ & Extremely Required
\end{tabular}

Table 4, for a secondary job position for employment as rated by the Academic Sector. The participants of the Academic Sector gave a Grand Mean Score of 4.67 with a descriptive value of "Extremely Required" of which the highest rating is the Computer Programmer with a mean score of 4.85. As cited by Stokdyk (2021), computer programmer designs, develops and test software and ensure software adheres to best practices in performance, reliability and security. Computer programmers can work developing mobile applications, coding video games, programming websites and much more. 
Table 5. ICT skills required of a BSIT Graduate as a basis for an entry-level position (Primary \& Secondary Job Position) as rated by Industry \& Academic Sector.

\begin{tabular}{|c|c|c|c|c|c|}
\hline Sector & Entry-Level Position & $\begin{array}{l}\text { Grand } \\
\text { Mean }\end{array}$ & $\begin{array}{c}\text { Overall Grand } \\
\text { Mean }\end{array}$ & $\begin{array}{c}\text { Combined } \\
\text { Overall } \\
\text { Grand Mean }\end{array}$ & Description \\
\hline \multirow[t]{2}{*}{ INDUSTRY } & Primary Job Position & 3.96 & 3.98 & \multirow{4}{*}{4.23} & \multirow{4}{*}{$\begin{array}{l}\text { Extremely } \\
\text { Required }\end{array}$} \\
\hline & Secondary Job Position & 3.99 & & & \\
\hline \multirow[t]{2}{*}{ ACADEMIC } & Primary Job Position & 4.31 & 4.49 & & \\
\hline & Secondary Job Position & 4.67 & & & \\
\hline
\end{tabular}

Table 5, presents the Overall Grand Mean Score of 4.23 with a descriptive value of "Extremely Required" for Primary \& Secondary entry level position rated by both the Industry and Academic Sector. This implies further that both sector have similar selection in terms of hiring BSIT Graduate for entry-level position in the industry.

Problem No. 2. What is the level of competency or proficiency of the BSIT Graduates as required for an entry-level position in the IT Department?

Table 6. Level of competency or proficiency of BSIT Graduates as rated by Industry (Professional Course)

\begin{tabular}{|c|c|c|c|}
\hline No. & Skills in Professional Course & Computed Mean & Description \\
\hline 1 & Database Management System & 4.57 & Expert \\
\hline 2 & Information Management & 4.40 & Expert \\
\hline 3 & Quantitative Methods with Simulation & 4.27 & Expert \\
\hline 4 & System Analysis and Design & 4.27 & Expert \\
\hline 5 & Advance Database Systems & 4.28 & Expert \\
\hline 6 & Software Engineering & 4.27 & Expert \\
\hline 7 & System Integration \& Architecture 1 & 4.17 & Advanced \\
\hline 8 & System Integration \& Architecture 2 & 4.05 & Advanced \\
\hline 9 & Networking 1 & 4.15 & Advanced \\
\hline 10 & Networking 2 & 4.27 & Expert \\
\hline 11 & Introduction to Human Computer Interaction & 4.08 & Advanced \\
\hline 12 & Multimedia Systems & 4.02 & Advanced \\
\hline 13 & Information Assurance and Security 1 & 3.90 & Advanced \\
\hline 14 & Capstone Project and Research 1 & 3.83 & Advanced \\
\hline 15 & Capstone Project and Research 2 & 4.02 & Advanced \\
\hline 16 & Social and Professional Issues & 4.15 & Advanced \\
\hline 17 & Application Development \& Emerging Technologies & 4.10 & Advanced \\
\hline 18 & System Administration and Maintenance & 4.35 & Expert \\
\hline Le & $\begin{array}{l}\text { GRAND MEAN } \\
\text { 1: Expert (E) - 4.21 - 5.00; Advanced (A) - } 3.41-4.20 \\
\text { Awarenes }\end{array}$ & $\begin{array}{c}\mathbf{4 . 1 7} \\
1-3.40 ; \text { Novice }(1\end{array}$ & $\begin{array}{c}\text { Advanced } \\
\text { Fundamental }\end{array}$ \\
\hline
\end{tabular}

Table 6, presents the computed mean for level of competency or proficiency of the BSIT Graduates as rated by Industry in terms of skills in Professional Course. Database Management System had the highest mean score of 4.57 with a descriptive value of "Expert". The overall mean was 4.17 with a descriptive value of "Advanced". 
Table 7. Level of competency or proficiency of the BSIT Graduates as rated by Industry (Common Course)

\begin{tabular}{llcr} 
No. & Common Course & Computed Mean & Description \\
\hline 1 & Introduction to Computing & 4.10 & Advanced \\
\hline 2 & Computer Programming I & 4.22 & Expert \\
\hline 3 & Computer Programming 2 & 3.88 & Advanced \\
\hline 4 & Discrete Structures 1 & 3.98 & Advanced \\
\hline 5 & Data Structures and Algorithms & 4.17 & Advanced \\
\hline 6 & Web Programming \& Development & $\mathbf{4 . 0 8}$ & Advanced \\
\hline & GRAND MEAN & Advanced
\end{tabular}

Table 7, shows the computed mean for level of competency or proficiency of the BSIT Graduates as rated by Industry in terms of the skills of the Common Courses of the BSIT Program. Computer Programming had the highest mean score of 4.22 with a descriptive value of "Expert". The Grand Mean was 4.08 with a descriptive value of "Advanced".

Table 8. Level of competency or proficiency of the BSIT Graduates as rated by Industry (Elective Course)

\begin{tabular}{llcc} 
No. & Elective Course & Computed Mean & Description \\
\hline 1 & Object Oriented Programming & 3.95 & Advanced \\
\hline 2 & Platform Technologies & 3.95 & Advanced \\
\hline 3 & Integrative programming \& Technologies I & 3.87 & Advanced \\
\hline 4 & Integrative programming \& Technologies II & 3.77 & Advanced \\
\hline & GRAND MEAN & $\mathbf{3 . 8 8}$ & Advanced
\end{tabular}

Table 8, shows the computed mean for level of competency or proficiency of the BSIT Graduates as rated by Industry in terms of the skills in Elective Courses of the BSIT Program. Object Oriented Programming and Platform Technologies had the highest mean score of 3.95 with a descriptive value of "Advanced" so as the Grand Mean with computed mean value of 3.88 .

Table 9. Level of competency or proficiency of the BSIT Graduates as rated by Industry in Professional, Common \& Elective Course

\begin{tabular}{llccc} 
No. & Course & Grand Mean & Description \\
\hline 1 & Professional & 4.17 & Expert \\
\hline 2 & Common & 4.08 & Advanced \\
\hline 3 & Elective & 3.88 & Advanced \\
\hline & OVERALL GRAND MEAN & $\mathbf{4 . 0 5}$ & Advanced
\end{tabular}

Table 9, shows the computed mean for professional, Common and Elective course. The highest computed mean was 4.17 for Professional with a descriptive value of "Expert". This implies that the BSIT Graduates should have an "Expert" Level of competency or proficiency in their Professional Course starting on Database Management System, Information Management, System Administration and Maintenance, Advance Database Systems, Quantitative Methods with Simulation, System Analysis and Design, Software Engineer, Networking and Computer Programming as rated by Industry sector and considered as the top highest paying jobs in the country as mentioned in the published article of (DOLE, 2019). 
Table 10. Level of competency or proficiency of BSIT Graduates as rated by Academic (Professional Course)

\begin{tabular}{|c|c|c|c|}
\hline No. & Skills in Professional Course & Computed Mean & Description \\
\hline 1 & Database Management System & 4.60 & Expert \\
\hline 2 & Information Management & 4.08 & Advanced \\
\hline 3 & Quantitative Methods with Simulation & 4.22 & Expert \\
\hline 4 & System Analysis and Design & 4.55 & Expert \\
\hline 5 & Advance Database Systems & 4.37 & Expert \\
\hline 6 & Software Engineering & 4.40 & Expert \\
\hline 7 & System Integration \& Architecture 1 & 4.10 & Advanced \\
\hline 8 & System Integration \& Architecture 2 & 4.30 & Expert \\
\hline 9 & Networking 1 & 4.63 & Expert \\
\hline 10 & Networking 2 & 4.57 & Expert \\
\hline 11 & Introduction to Human Computer Interaction & 3.83 & Advanced \\
\hline 12 & Multimedia Systems & 3.88 & Advanced \\
\hline 13 & Information Assurance and Security 1 & 4.13 & Advanced \\
\hline 14 & Capstone Project and Research 1 & 4.20 & Advanced \\
\hline 15 & Capstone Project and Research 2 & 4.25 & Expert \\
\hline 16 & Social and Professional Issues & 3.98 & Advanced \\
\hline 17 & Application Development \& Emerging Technologies & 3.87 & Advanced \\
\hline \multirow[t]{2}{*}{18} & System Administration and Maintenance & 4.55 & Expert \\
\hline & GRAND MEAN & 4.25 & Advanced \\
\hline
\end{tabular}

Table 10, presents the computed mean for level of competency or proficiency of the BSIT Graduates as rated by Academic in terms of skills in Professional Course. Networking 1 had the highest mean score of 4.63 with a descriptive value of "Expert", then followed by Database Management System with a mean score of 4.60, Networking 2 with a mean score of 4.57, System Administration and Maintenance \& System Analysis and Design with both had a mean score of 4.55, and Software Engineering with a mean score of 4.40. For a mean score of "Advanced" in their descriptive value starting with Introduction to Human Computer Interaction with a mean score of 3.83, Application Development \& Emerging Technologies with a mean score of 3.87, and Multimedia Systems with a mean score of 3.88. The Grand Mean for this was 4.25 with a descriptive value of "Advanced".

Table 11. Level of competency or proficiency of the BSIT Graduates as rated by Academic (Common Course)

\begin{tabular}{llcc} 
No. & Common Course & Computed Mean & Description \\
\hline 1 & Introduction to Computing & 3.98 & Advanced \\
\hline 2 & Computer Programming I & 4.48 & Expert \\
\hline 3 & Computer Programming 2 & 4.50 & Expert \\
\hline 4 & Discrete Structures 1 & 4.05 & Advanced \\
\hline 5 & Data Structures and Algorithms & 4.45 & Expert \\
\hline 6 & Web Programming \& Development & 4.45 & Expert \\
\hline & GRAND MEAN & $\mathbf{4 . 3 2}$ & Expert
\end{tabular}

Table 11, shows the computed mean for the Common Courses of the BSIT Program. Computer Programming, I \& 2 had the highest mean score of $4.50 \& 4.48$ with a descriptive value of "Expert", then followed by Web Programming \& Development and Data Structures and Algorithms with a mean score of 4.45. Introduction to Computing had a mean score of 3.98 with a descriptive value of "Advanced". The Grand mean for was 4.32 with a descriptive value of "Expert". 
Table 12. Level of competency or proficiency of the BSIT Graduates as rated by Academic (Elective Course)

\begin{tabular}{llccc} 
No. & Elective Course & Computed Mean & Description & Expert \\
\hline 1 & Object Oriented Programming & 4.38 & 4.22 & Expert \\
\hline 2 & Platform Technologies & 4.48 & Expert \\
\hline 3 & Integrative programming \& Technologies I & 3.78 & Advanced \\
\hline 4 & Integrative programming \& Technologies II & $\mathbf{4 . 2 2}$ & Expert
\end{tabular}

Table 12, shows the computed mean for level of competency or proficiency of the BSIT Graduates as rated by Academic in terms of the skills in Elective Courses of the BSIT Program. Integrative Programming and Technologies I had the highest mean score of 4.48 with a descriptive value of "Expert". The overall mean was 4.22 with a descriptive value of "Expert".

Table 13. Level of competency or proficiency of the BSIT Graduates as rated by Academic in Professional, Common \& Elective Course

\begin{tabular}{llcc} 
No. & Course & Grand Mean & Description \\
\hline 1 & Professional & 4.25 & Expert \\
\hline 2 & Common & 4.32 & Expert \\
\hline 3 & Elective & 4.22 & Expert \\
\hline & OVERALL GRAND MEAN & $\mathbf{4 . 2 6}$ & Expert
\end{tabular}

Table 13, shows the computed mean for Professional, Common and Elective Course with an Overall Grand Mean of 4.26 with "Expert" description. This implies that the BSIT Graduates should have an "Expert" Level of competency or proficiency in their Professional, Common and Elective Course as rated by the Academic sector. It could be inferred further that the Academe of the different State Universities and Colleges (SUCs) and private Higher Education Institutions (HEIs) should focus on mastering the competency of all three courses listed in the curriculum of BSIT Program. According to (Harmse, 2018), Higher Education institutions should have an understanding of the ICT industry regarding their expected skillset of ICT graduates that will prepare them for employment in the industry.

Problem No. 3. Is there a significant difference in the level of competency or proficiency of the BSIT Graduates as required for an entry-level position in the IT Department as rated by the Academic and the Industry Sector?

Table 14. Significant Difference in the Level of Competency or Proficiency of the BSIT Graduates as required for an entry-level position in the IT Department as rated by the Academic and the Industry Sector

\begin{tabular}{cccccc} 
Variable & Mean Response & t-value & P-value & Remarks & Decision \\
\hline Industry & 4.05 & -2.376 & .019 & Not Significant
\end{tabular}

Note: P-value is greater than alpha $=0.05$; Null hypothesis is not rejected.

$\mathrm{P}$-value is less than alpha $=0.05$; Null hypothesis is rejected.

Table 14, shows t-test results in the Level of Competency or Proficiency of the BSIT Graduates as required for an entry-level position in the IT Department as rated by the Academic and the Industry Sector.

T-test for independent samples was used to establish the difference between variables. Since the P-value is greater than 0.05 level of significance, this means that there is no significant difference in the level of competency or proficiency of the BSIT Graduates as required for an entry-level position in the IT Department 
as rated by the Academic and the Industry Sector. The rule is to Accept Ho, if the P-value is greater than 0.05 level of significant which is indicated in the table. This can be inferred, that the rating of the industry and academic sector are more or less the same. It only signifies further that the BS Information Technology Curriculum of the State Universities and Colleges (SUCs) and private Higher Educational Institutions (HEIs) in Zamboanga Peninsula are aligned to the demands of the industry in terms of the required ICT skills competency in Database Management System, Information Management, System Administration and Maintenance, Advance Database Systems, Quantitative Methods with Simulation, System Analysis and Design, Software Engineer, Networking and Computer Programming.

\section{Conclusion}

\section{Based on the findings, the following conclusions were drawn:}

1. Both Industry and Academic sectors rated extremely required Technical Support Specialist, System Administrator, Web and Applications Developer, Network Engineer and Computer Programmer in the entry-level position in the IT Department.

2. An expert level is necessary in terms of the competency or proficiency in Managing Database System, Networking, and Programming both for Web and Computer as well as system design, analysis, administration, and maintenance. He/she can provide guidance, troubleshoot, and answer questions related to this area of expertise and the field where the skill is used.

3. State Universities and Colleges (SUCs) and private Higher Education Institutions (HEIs) and the different industry sectors in the Zamboanga Peninsula have the same requirements in hiring BSIT graduates for an entry-level position that have acquired ICT skills experts in their professional and common courses.

\section{Recommendation}

\section{Based on the findings the following recommendations were made:}

1. The BS Information Technology program of the different State Universities and Colleges (SUCs) and private Higher Education Institutions (HEIs) should enhance linkages to its industry stakeholders to keep up and be updated to the demands of the industry workforce in terms of hiring BSIT graduates.

2. School Administrator or Dean of the College should devise training workshop for ICT Instructors/Professors especially in areas like Networking, System analysis and Design, Computer \& Web programming and Database Management System to enhance the level of competency or proficiency of the BSIT students.

3. The Dean or Administrator of the College should conduct monitoring and class observations to see to it that the IT Instructors/Professors are giving emphasis and concentrating more on the competencies which the industries noted as extremely required and encourage students to take a National Certificate or NC of Technical Education And Skills Development Authority (TESDA) in Computer System Servicing and Computer and Web Programming to be competent for a greater chance of employment as an entry-level position in the industry.

4. The Dean or Administrator of the BSIT program must pursue a higher level of accreditation to further enhance the curriculum in order to be at par of the program needs of the industry in aligning and matching the required needed ICT competency of the BSIT graduates. 


\section{References}

Bukas.ph. (2021). bukas.ph. Retrieved from bukas.ph: https://bukas.ph/blog/7-in-demand-ict-careers-in-thephilippines/

CMO25. (2015). REVISED POLICIES, STANDARDS, AND GUIDELINES FOR BACHELOR OF SCIENCE IN INFORMATION TECHNOLOGY (BSIT).

DOLE. (2019, March). LABOR MARKET TRENDS. Retrieved from BUREAU OF LOCAL EMPLOYMENT: http://www.ble.dole.gov.ph/downloads/Publications/LMT/LMI-LMT-

Top\%2010\%20Highest\%20Paying\%20\%20Jobs-March\%202019\%20Issue.pdf

Harmse, A. (2018, July). epository webpage. Retrieved from epository website: http://repository.nwu.ac.za/handle/10394/31628

Martinez, J. M. (2018). Mesacc Education. Retrieved March 12, 2018, from Messac Website: https://www.scribd.com/document/320379452/Curriculum-Development-1

Miltner, K. M. (2017, December 9).theconversation company. Retrieved March 12, 2018, from theconversation Website: https://theconversation.com/taking-a-second-look-at-the-learn-to-codecraze-86597

Stokdyk, D. (2021, April 6). Become a Programmer. Retrieved from snhu: https://www.snhu.edu/aboutus/newsroom/stem/what-do-programmers-do 